Chaim Samuel Hönig. Volterra-Stieltjes integral equations with linear constraints and discontinuous solutions

Roger Howe and Allan Silberger. Why any unitary principal series representation of $S L_{n}$ over a $p$-adic field decomposes simply .....

F. A. Howes. Some singular perturbation problems

Carlos E. Kenig and Horacio Porta. Weak continuity of Banach algebra products

Igor Kluvánek. The range of a vector measure ..................................... 609

Zeev Nehari. Riccati systems

Reese T. Prosser. A double scale of weighted $L^{2}$ spaces ................... 615

Jih-Min Shyr. On the norm form of a finite Galois extension over Q 619

Jonathan D. Sondow. When is a manifold a leaf of some foliation? ....

Myron M. Sussman. On uniqueness in Cauchy's problem for elliptic

operators with characteristics of multiplicity greater than two ..

Joseph L. Taylor. A counterexample in shape theory

Robert J. Zimmer. Extensions of ergodic actions and generalized discrete spectrum

Corrigendum, Volume 80

\title{
COUNCIL, 1975
}

\section{PUBLICATIONS COMMITTEES*}

Robert G. Bartle, Hyman Bass, James H. Bramble, Glen E. Bredon, Edgar H. Brown, Jr., Alberto P. Calderón, S. S. Chern, Philip T. Church, W. Wistar Comfort, Chandler Davis, Samuel Eilenberg, Robert M. Fossum, Walter Gautschi, Richard R. Goldberg, Paul R. Halmos, Alston S. Householder, Alexandra Ionescu-Tulcea, John L. Kelley, Alistair H. Lachlan, D. J. Lewis, Richard K. Miller, Barbara L. Osofsky, Jacob T. Schwartz, Stephen S. Shatz, I. M. Singer, Daniel W. Stroock, François Treves, Hans F. Weinberger, John W. Wrench, Jr.

\section{OTHER MEMBERS OF THE COUNCIL}

Paul Bateman, Anatole Beck, Lipman Bers, Raoul H. Bott, Charles W. Curtis, David Gale, Leonard Gillman, Michael Golomb, Walter Gottschalk, Mary W. Gray, Judy Green, Phillip A. Griffiths, Orville G. Harrold, Jr., Irving Kaplansky, Herbert B. Keller, Robion C. Kirby, Lee Lorch, Saunders Mac Lane, Arthur P. Mattuck, John W. Milnor, Cathleen S. Morawetz, Karl K. Norton, Franklin Peterson, Everett Pitcher, Murray H. Protter, Kenneth A. Ross, Jane Cronin Scanlon, J. Ernest Wilkins, Jr.

\footnotetext{
* Research announcements, limited to 100 typed lines of 65 spaces each, may be submitted to those members of the Council who are members of the publications committees. Such announcements are intended to communicate outstanding results that are to be reported in full elsewhere.
} 


\section{CONTENTS}

May, 1975

Sigurdur Helgason. Review of "Strong rigidity of locally symmetric spaces" by G. D. Mostow

C. E. Rickart. Review of "Complete normed algebras" by F. F. Bonsall and J. Duncan

Richard V. Kadison. Review of "The structure of factors" by S. Anastasio and P. M. Willig

Walter L. Baily, Jr. Review of "Topics in complex function theory" by Carl L. Siegel

Herbert S. Wilf. Review of "Algebraic graph theory" by Norman Biggs and "Combinatorial theory seminar" by Jacobus $H$. van Lint

J. R. Isbell. Review of "Values of non-atomic games" by R. J. Aumann and L. S. Shapley

Harold Widom. Review of "Convolution equations and projection methods for their solution" by I.C. Gohberg and I. A. Fel'dman

Elections to membership

Michael O. Albertson and Joan P. Hutchinson. The maximum size of an independent set in a nonplanar graph

D. L. Burkholder. $H^{p}$ spaces and exit times of Brownian motion

Sylvain E. Cappell and Julius L. Shaneson. Invariants of 3-manifolds

C. K. Chui, P. W. Smith and J. D. Ward. Limits of $H^{k, p}$-splines ....... 563

Robert Connelly. An attack on rigidity. I, II ..................................... 566

William C. Connett and Alan L. Schwartz. Unifying multiplier theorems of Hörmander, Marcinkiewicz, and Michlin type

Vinay V. Deodhar. On central extensions of rational points of algebraic groups

James A. Donaldson. The Cauchy problem for a first order system of abstract operator equations

Theodore Frankel. Applications of Duschek's formula to cosmology and minimal surfaces

Dennis Garbanati. Extensions of the Hasse norm theorem ............... $\quad 583$

William Hanf. The Boolean algebra of logic

Dennis A. Hejhal. Monodromy groups for higher-order differential equations 